Europe, and so long ago as I 844 a more extended tour in South Italy and Sicily. In this country he was so well known that British entomologists will feel that in his death they have lost one of themselves; it is nearly thirty-five years since he was elected an Honorary Member of the Entomological Society of London, and he was one of the editors of Mr. Stainton's magnificent "Natural History of the Tineina." There are those amongst us in this country who in Zeller's death have lost one of their dearest friends. Scientific entomology has lost one of its most shining lights.

R. MCLACHLAN

\section{THE GREAT INTERNATIONAL FISHERIES EXHIBITION}

HER MAJESTY THE QUEEN has recently appointed the I2th of May for the opening of the International Fisheries Exbibition, which an influential and energetic committee, under the active presidency of the Prince of Wales, has developed to a magnitude undreamt of by those concerned in its early beginnings. This magnitude is perhaps as great a matter of agreeable surprise to Mr. Birkbeck and its other Norwich founders as it will be to those who have very naturally become accustomed to class all specific exhibitions together upon a standard formed by the unfortunate annual exhibitions of which the public has, not without reason, grown weary.

The idea of an international Fisheries Exhibition arose out of the success of the show of British fishery held at Norwich a short time ago : and the president and executive of the latter formed the nucleus of the far more powerful body by whom the present enterprise has been brought about.

The buildings are well advanced towards completion, and will be finished long before the opening day; the exhibitors will, it is hoped, support the executive by sending in their goods in time, and thus all will be ready for the 12 th proximo.

The plan of the buildings embraces the whole of the twenty-two acres of the Horticultural Gardens: the upper half, left in its usual state of cultivation, will form a pleasant lounge and resting-place for visitcrs in the intervals of their study of the collections. This element of garden accommodation was one of the most attractive features at the Paris Exhibition of 1878 .

As the plan of the buildings is straggling and extended, and widely separates the classes, the most convenient mode of seeing the show will probably be found in going through the surrounding buildings first, and then taking the annexes as they occur.

On entering the main doors in the Exhibition Road, we pass through the Vestibule to the Council Room of the Royal Horticultural Society, which has been decorated for the reception of marine paintings, river subjects, and fish pictures of all sorts, by modern artists.

Leaving the Fine Arts behind, the principal builfing of the Exhibition is before us-that devoted to the deep sea fisheries of Great Britain. It is a handsome wooden structure $750 \mathrm{ft}$. in ler gth, $50 \mathrm{ft}$. wide, and $30 \mathrm{ft}$. at its greatest heigbt. The model of this, as well as of the other temporary wooden buildings, is the same as that of the annexes of the great Exhibition of 1862 .

On our left are the Dining Rooms with the Kitchens in the rear. The third room, set apart for cheap fish dinners (one of the features of the Exhibition), is to be decorated at the expense of the Baroness Burdett Coutts, and its walls are to be hung with pictures lent by the Fishmongers' Company, who have also furnished the requisite chairs and tables, and have made arrangements for a daily upply of cheap fish, while almost everything necessary to its maintenan se (forks, spoons, table-linen, \&c.), will be lent by various firms.
The apsidal building attached is to be devoted to lectures on the cooking of fish.

Having crossed the British Section, and turning to the right and passing by another entrance, we come upon what will be to all one of the most interesting features of the Exhibition, and to the scientific student of ichthyology a collection of paramount importance. We allude to the Western Arcade, in which are placed the Aquaria, which have in their construction given rise to more thoughtful care and deliberation than any other part of the works. On the right, in the bays, are the twenty large asphalt tanks, about $\mathrm{I} 2 \mathrm{ft}$. long, $3 \mathrm{ft}$. wide, and $3 \mathrm{ft}$. deep. These are the largest dimensions that the space at command will allow, but it is feared by some that they will be found somewhat confined for fast going fish. Along the wall on the left are ranged twenty smaller or table-tanks of slate, which vary somewhat in size; the ten largest are about $5 \mathrm{ft} .8 \mathrm{in}$. long, $2 \mathrm{ft} .9$ in. wide, and $\mathrm{Ift} .9$ in. deep.

In this Western Arcade will be found all the new inventions in fish culture-models of hatching, breeding and rearing establishments, apparatus for the transporting of fish, ova, models, and drawings of fish-passes and ladders, and representations of the development and growth of fish. The chief exhibitors are specialists, and are already well known to our readers. Sir James Gibson Maitland has taken an active part in the arrangement of this branch, and is himself one of the principal contributors.

In the north of the Arcade where it curves towards the Conservatory, will be shown an enormous collection of examples of stuffed fish, contributed by many of the prominent angling societies. In front of these on the counter will be ranged microscopic preparations of parasites, \&c., and a stand from the Norwich Exhibition of a fauna of fish and fish-eating birds.

Passing behind the Conservatory and down the Eastern Arcade-in which will be arranged Algx, Sponges, Mollusca, Star-fish, worms used for bait, insects which destroy spawn or which serve as food for fish, \&c.--on turning to the left, we find ourselves in the Fish Market, which will probably vie with the Aquaria on the other side in attracting popular attention. This model Billingsgate is to be divided into two parts, the one for the sale of fresh, the other of dried and cured fish.

Next in order come the two long iron sheds appropriated respectively to Life-boats and Machinery in motion. Then past the Royal Pavilion (the idea of which was doubtless taken from its prototype at the Paris Exhibition) to the southern end of the central block, which is shared by the Netherlands and Newfoundland; ju:t to the north of the former Belgium has a place.

While the Committee of the Netherlands was one of the earlie:t formed, Belgium only came in at the eleventh hour ; she will, however, owing to the zealous activity of Mr. Lenders, the Consul in I.ondon, send an important contribution worthy of her interest in the North Sea fisheries. We ought also to mention that New foundland is among those colonies which have shown great energy, and she may be expected to send a large collection.

Passing northward we come to Sweden and Norway, with Chili between them. These two countries were, like the Netherlands, early in freparing to participate in the Exhibition. Each has had its own Committee, which has been working hard since early in 1882 .

Parallel to the Scandinavian section is that devoted to Canada and the United States. While the American Government has frei hted a ship with specimens expected daily, the former has entered heart and soul into the friendly rivalry, and will occupy an equal space---ten thousand square feet.

In the Northern Transept will be placed the inland fisheries of the United Kingdom. At each end of the building is aptly inclosed a basin formerly standing in the gardens: and over the eastern one will be erected the 
daïs from which the Queen will formally declare the Exhibition open.

Shooting out at right angles are the Spanish annexe, and the building shared by India and Ceylon, China and Japan, and New South Wales: while corresponding to these at the western end are the Russian annexe and a shed allotted to several countries and colonies. The Isle of Man, the Bahamas, Switzerland, Germany, Hawaii, Italy, and Greece-all find their space under its roof.

After all the buildings were planned, the Governments of Russia and Spain declared their intention of participating; and accordingly for each of these countries a commodious iron building has been specially erected.

The Spanish collection will be of peculiar interest; it

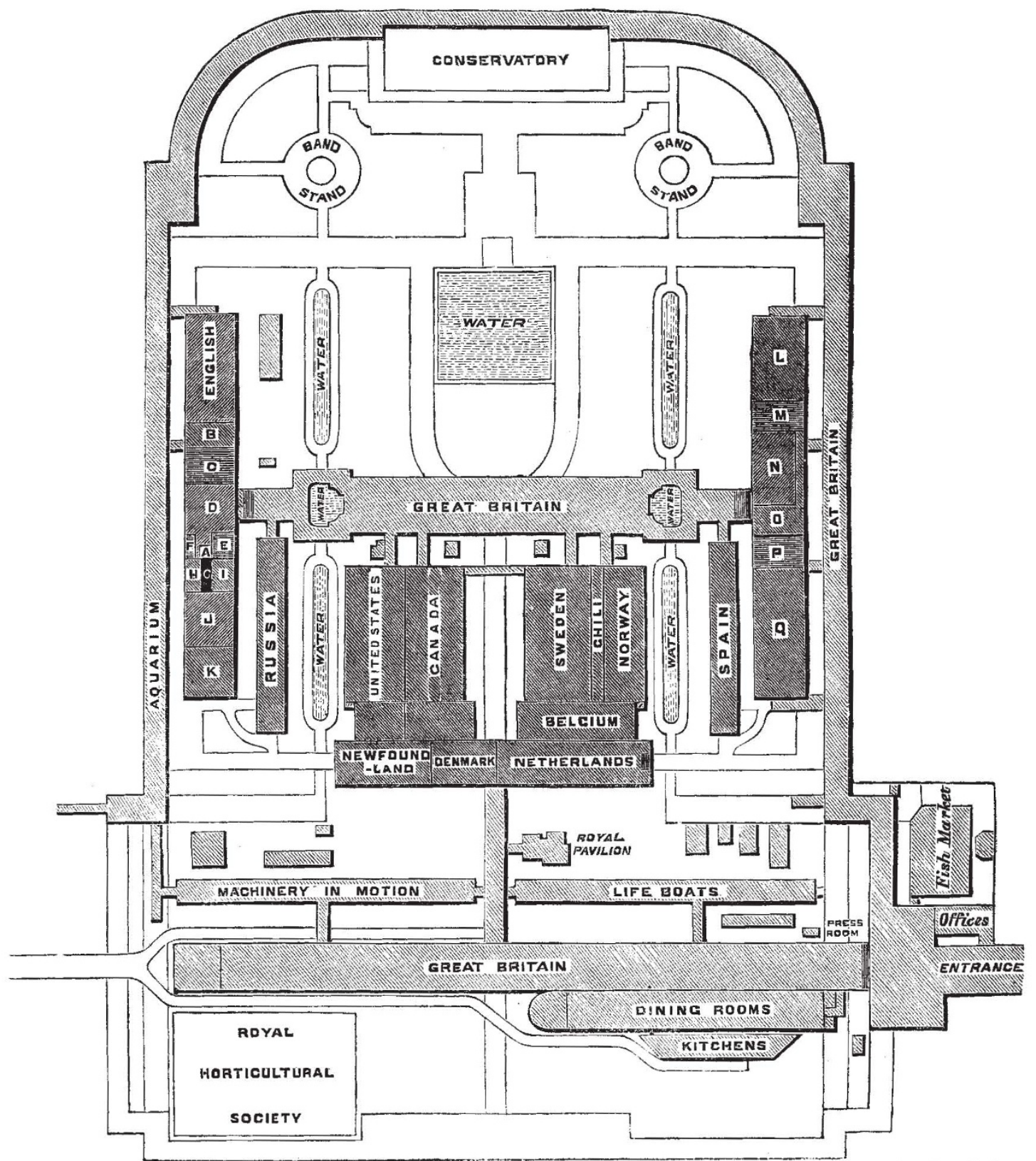

ELOCK Plan.-A. Swilzerland; B. Isle of Man; C. Bahama and W. I. Islands; D. Hawaii ; E. Poland; F. Portugal; G. Austria ; H. Germany; I. France : J Italy; K. Greece; L. China ; M. India and Ceplon; N. Straits Settlements ; O. Japan; P. Tasmania; Q. New South Wales. -Scale, 200 feet to the inch.

has been gathered together by a Government vessel ordered round the coast for the furpose, and taking up contributions at all the seaports as it passed.

of the countries whose Governments for inscrutable reasons of state show disfavour and lack of sympathy, Germany is prominent ; although by the active initiative of the London Committe some important contributions have keen secured from frivate individuals: among them, we are happy to say, is Mr. Max von dem Rorne, who will send his celebrated incubators, which the English Ccmmittee have arranged to exhibit in operation at their own exrense.

Although the Italian Government, like that of Germany, holds aloof, individuals, esfecially Dr. Dohrn of the 
Naples Zoological Station, will send contributions of great scientific value.

France, the other day only, consented to the official appointment of her Consul to look after the interests of the oyster cultivators who are contributing an important feature.

In the Chinese and Japanese annexe, on the east, will be seen a large collection of specimens (including the gigantic crabs) which has been collected, to a great extent, at the suggestion of Dr. Günther of the British Museum.

It is at the same time fortunate and unfortunate that a similar Fisheries Exhibition is now being held at Yokohama, as many specimens which have been collected specially for their own use would otherwise be wanting; and on the other hand, many are held back for their own show.

China, of all foreign countries, was the first to send her goods, which arrived at the building on the 3oth ultimo, accompanied by native workmen, who are preparing to erect over a basin contiguous to their annexe models of the summer-house and bridge with which the willowpattern plate has made us familiar; while on the basin will float models of Chinese junks.

Of British colonies, New South Wales will contribute a very interesting collection placed under the care of the Curator of the Sydney Museum; and from the Indian Empire will come a large gathering of specimens in spirits under the superintendence of Dr. Francis Day.

Of great scientific interest are the exhibits, to be placed in two neighbouring sheds, of the Native Guano Company and the Millowners' Association. The former will show all the patents used for the purification of rivers from sewage, and the latter will display in action their method of rendering innocuous the chemical pollutions which factories pour into rivers.

In the large piece of water in the northern part of the gardens, which has been deepened on purpose, apparatus in connection with diving will be seen; and hard by, in a shed, Messrs. Siebe, Gorman \& Co. will show a selection of beautiful minute shells dredged from the bottom of the Mediterranean.

In the open basins in the gardens will be seen beavers, seals, sea-lions, waders, and other aquatic birds.

From this preliminary walk round enough has, we think, been seen to show that the Great International Fisheries Exhibition will prove of interest alike to the ordinary visitor, to those anxious for the well-being of fishermen, to fishermen themselves of every degree, and to the scientific student of ichthyology in all its branches.

The economic question of the undertaking we have left untouched.

\section{NOTES}

IT will be seen from a communication in another column that the Council of the British Association have virtually decided that that body is bound to hold its meeting in Canada in 1884 . From Sir A. T. Galt's letter it is evident that our Canadian fellowsubjects have already arranged to give the Association a hearty and generous welcome; and now that Canada seems inevitable, ne hope that as many members as possible will make up their minds to be present. The expenses for visitors will be reduced to a minimum, a $d$ the travelling expenses of officials, to the number of fifty, to nil. A magnificent programme for three weeks' excursions has been sketched, and the expenses connected with them will be confined to hotel charges, carriages, \&c., the railway companies having handsomely offered to convey members free of charge.

THE Academy of Sciences held its Annual Meeting on April 2, M. Jamin in the chair. He pronounced the éloge of the three Academicians who died last year, viz., MM. Liouville,
Bussy, and Decaisne. M. Blanchard, filling the room of $M$. Dumas, who, although present, was unable to deliver any speech, read the list of laureates. The number of prizes offered for public competition is yearly enlarging; not less than three of them-Monti, Machedo, and Francœur-were delivered for the first time. The number of verdicts which the commission had to render was thirty-three. In nine cases the commission declared no memoir was worthy to take a prize; the competitions were in general adjourned to 1885 , and a certain sum of money was given to some semi-successful candidates. In two instances the merit of the candidates was acknowledged so great that two prizes were delivered instead of one. These two cases were in statistics and mathematics; the question put was to give a theory of the partition of numbers in five squares. Amongst the prizes lost is included the famous Prix Breaux, for the cure of cholera. The interest was divided amongst four pupils of M. Pasteur's. The Poncelet Prize has been taken by M. Clansius, and the Voltz Prize by Mr. Huggins and M. Crüls, a Brazilian, for their spectroscopic work.

Ir was announced at the a ove-mentioned meeting that the great mathematical prize of the French Academy had been awarded to the late Prof. H. J. S. Smith for his dissertation on the representation of a number as the sum of five squares. The subject for the prize was announced in the Comptes Rendu of the Academy in February of last year, and, accoriing to custom, the essays were to be sent in before June $\mathbf{I}$-each dissertation bearing a motto and being accompanied by a sealed envelope having the motto on the outside and the writer's name inside. The envelopes of the unsuccessful candidates are destroyed unopened. Prof. Smith's dissertation bore as its appropriate motto :-

"Quotque, quibusque modis possint in quinque resolvi Quadratos numeri pagina nostra docet.'

There were three candidates, and the value of the prize is 3000 . The theory of numbers, to which the prize subject related, is one to which Prof. Smith had devoted the greater part of his life, and in which he occupied an almost unique position; with the exception of Prof. Kummer of Berlin, there is no one whose contributions to the science could be compared to his, and this pusthumous mark of the appreciation on the Continent of the value of his work is all the more satisfactory as the great prize has never before, we believe, been awarded to an English mathema. tician. The complete solution of the important problem pro. posed by the French Academy had been obtained by Prof. Smith sixteen years ago as part of a far more general investigation, and the results were published by him in the Proceedings of the Royal Society in 1868 , but without demonstration. These researches seem, however, to have escaped the notice of the French mathematicians. When the subject of the prize was announced last year, Prof. Smith extracted from his manuscript books the demonstrations of the propositions relating to the five-square problem, and it is to the dissertation so formed that the prize has been awarded. No more striking instance of the extent to which Prof. Smith had carried his researches, or of his great mathematical genius, could be given than is afforded by the fact that a question considered by the French Academicians of so much importance to the advancement of mathematical science as to be chosen for the subject of the "Grand Prix" should have been completely solved by him as only a particular case in the treatment of a general and even more intricate problem. In 1868 Prof. Snith won the Steiner Prize of the Berlin Academy, so that had he but lived till now he would have been "laureate" of the Academies of both Paris and Berlin.

THE removal of the natural history collection from Great Russell Street to its new quarters at South Kensington, on the 